\title{
Vinyl Chloride
}

National Cancer Institute

\section{Source}

National Cancer Institute. Vinyl Chloride. NCI Thesaurus. Code C936.

A chlorinated hydrocarbon occurring as a colorless, highly flammable gas with a mild, sweet odor that may emit toxic fumes of carbon dioxide, carbon monoxide, hydrogen chloride and phosgene when heated to decomposition. Vinyl chloride is primarily used to make polyvinyl chloride to manufacture plastics. Exposure to this substance affects the central and peripheral nervous system and causes liver damage. Prolonged exposure to vinyl chloride can cause a set of symptoms that is characterized by Raynaud's phenomenon, joint and muscle pain and scleroderma-like skin changes. Vinyl chloride is a known human carcinogen and is associated with an increased risk of developing liver cancer, predominantly angiosarcoma of the liver, but is also linked to brain and lung cancer as well as cancer of the lymphatic and hematopoietic system. ( $\mathrm{NCl05)}$ 